\title{
ЗАСТОСУВАННЯ ПОЛЯРИЗОВАНОГО СВІТЛА ПРИ ХРОНІЧНОМУ БЕЗСОННІ ТА ЗАЛЕЖНОСТІ ВІД КУРІННЯ
}

\author{
Д. Тубіч, М. Скорбіч ${ }^{1}$ \\ Психіатрична клініка, Клінічний центр (Республіка Сербія) \\ ${ }^{1} /$ нститут ядерної медицини, Клінічний центр (Республіка Сербія)
}

\begin{abstract}
При лікуванні багаторічного безсоння у хворих із ситуаційним неврозом використовувався апарат БІОПТРОН-2. Після 10 щовечірніх сеансів сталася нормалізація процесу засинання, і сон протягом ночі підтримувався без додаткової медикаментозної терапії. При лікуванні хронічних курців апаратом БІОПтРОН-компакт 30 пацієнтів отримували щодобові аплікації ПАЙЛЕР-світлом протягом 10 діб на вушну раковину. Констатовано зменшення потреби куріння в 15-100\% випадків, а також бажання остаточно кинути цю звичку.
\end{abstract}

Ключевые слова: світлотерапія, поляризоване світло, БІОПТРОН, куріння, безсоння.

\section{ПРИМЕНЕНИЕ ПОЛЯРИЗОВАННОГО СВЕТА ПРИ ХРОНИЧЕСКОЙ БЕССОННИЦЕ И ЗАВИСИМОСТИ ОТ КУРЕНИЯ}

\author{
Д. Тубич, М. Скорбич ${ }^{1}$ \\ Психиатрическая клиника, Клинический чентр (Республика Сербия) \\ ${ }^{1}$ Институт ядерной медицины, Клинический центр (Республика Сербия)

\begin{abstract}
При лечении многолетней бессонницы у больных с ситуационным неврозом использовался аппарат БИОПТРОН-2. После 10 ежевечерних сеансов произошла нормализация процесса засыпания, и сон в течение ночи поддерживался без дополнительной медикаментозной терапии. При лечении хронических курильщиков аппаратом БИоПтРОНкомпакт 30 пациентов получали ежесуточные аппликации ПАЙлЕР-светом в течение 10 суток на ушную раковину. Отмечено уменьшение потребности курения в 15-100\% случаев, а также желание окончательно прекратить курение/
\end{abstract}

Ключові слова: светотерапия, поляризованный свет, БИоПТРОН, курение, бессонница.

\section{POLARIZED LIGHT APPLICATION AT CHRONIC INSOMNIA AND HABIT OF SMOKING}

\author{
D. Tubič, M. Skorbič ${ }^{1}$ \\ Clinics of Psychiatry, Clinical Center (Serbia) \\ ${ }^{1}$ Institute and Clinical Center of Nuclear Medicine (Serbia)
}

\begin{abstract}
In the treatment of patients with situational neurosis, which for years suffered from insomnia, we used a BIOPTRON-2 device. After 10 everyday evening sessions, the process of falling asleep was normalized, and night sleep was maintained with no additional drugs. A group of 30 patients with a chronic habit of intensive smoking was subjected to applications of BIOPTRON-2 generated PILER light for 10 days. In a considerable part of the tested persons, we noticed a decrease in the inclination for smoking and an increase in the wish for final putting an end to smoke.
\end{abstract}

Key words: light therapy, polarized light, BIOPTRON, smoking, insomnia.

\section{Вначале сотворил Бог небо и землю}

1. Земля же была безвидна и пуста, и тьма над бездною; и Дух Божий носился над водою.

2. И сказал Бог: да будет свет. И стал свет.

3. И увидел Бог свет, что он хорош; и отделил Бог свет от тьмы.

4. И назвал Бог свет днем, а тьму ночью. И был вечер, и было утро: день один.

(С. Д. Тубіч, М. Скорбіч 
Расстройства сна. Сон является периодическим и временным перерывом в бодрствовании, в котором моторная активность почти полностью прекращается, осознание окружающей среды максимально редуцируется, а порог реактивности и рефлексной раздражительности повышается.

По классификации ICD-10 расстройства сна разделены на две большие группы: G-47 органические расстройства сна и F-51 неорганические расстройства сна.

На функцию сна оказывают влияние мозговые структуры от продолговатого мозга, ствола мозга до каудального диэнцефалона (ретикулоталамокортикальная система). Невротрансмиттерами в процессе сна являются серотонин (ингибиция которого приводит к инсомнии, а повторное введение - к регулированию сна), норадреналин, нейропептиды (мелатонин, секреция которого зависит от ритма свет - тьма, и соматостанин), затем соматотропные гормоны, кортизол. Суточные (дневные) ритмы очень важны для нормального и здорового сна. Имеются многочисленные сдвиги в распределении бодрствования и сна. Две самые важные группы - переходные и продолжительные. Причинами некоторых из них являются: перемена часовых поясов (синдром «JAT LAG»), перемена рабочих смен, вредные привычки и др. Расстройства сна классифицируются как расстройства при засыпании («начальная бессонница»), в процессе сна («переходная бессонница»), раннее утреннее пробуждение («конечная бессонница»), комбинированные расстройства. К последним относятся сочетания с другими болезнями: шизофрения, маниакально-депрессивный психоз, алкоголизм (и другие зависимости), невралгические болезни (повреждения спинного мозга и сосудов мозга, инфекции центральной нервной системы, эпилепсия) и др.

Методы лечения инсомний включают гигиену сна, психотерапию, релаксацию, специфические психотерапевтические действия (сокращение или депривация сна, парадоксальное намерение: «оставайся бодрствующим!»), медикаментозные (лечение основного заболевания, анксиолитики, гипнотики), светотерапия.

Табакокурение сегодня является самой распространенной токсикоманией. С тех пор, как человек начал курить, он и начал бороться с этой вредной привычкой. Вплоть до конца Второй мировой войны эта борьба была стихийной. С созданием Всемирной организации здравоохранения (ВО3) начали проводить организованную международную кампанию против курения.
B ICD-10 внесена группа умственных расстройств и расстройств в поведении вследствие употребления табака (F-17), а также еще одна подгруппа (Z-72.0) - люди, для которых курение - образ жизни.

Терапия курения является достаточно комплексной и сложной. Известны различные индивидуальные подходы, групповые, организованные (в клиниках). Наиболее часто применяются следующие терапевтические подходы: использование лекарств (чаще всего анксиолитики), субстратов никотина (никотиновых жевательных резинок - nicorette), интрадермальных фластеров, назальных аэрозолей, ингаляторов, аверсивной терапии (электростимуляции), различных психотерапевтических методов. Известны и многие так называемые альтернативные методы: фитотерапия (лечение травяными чаями), гомеопатия и акупунктура (китайская традиционная медицина, т. е. введение различных игл в определенные участки тела, верхних и нижних конечностей, ушной раковины, головы; использование стимуляции точек с помощью определенного тока, лазера, магнитов, тепла). Наиболее часто используемыми акупунктурными точками при лечении от курения являются:

- туловище - UB(VU) 2, 12, 13, 14, 15, 16; ST(TR) 2; Li(IC) 10, 11, 20; Lu(P) 1; GB(VF) 20, 30, 33; SP(LP) 6; Liv(H) 3; ST(G) 13, 11;

- ушная раковина - shen men, P, IC, R, mouth, adrenal gland, hunger, subcortex.

- электротерапия - ушная раковина: lung, shen men, subcortex LI(IC) bill.; Gv(DM) 20, Lu(P) 6; GB(VF) 33.

Однако до сегодняшнего дня не зарегистрировано ни одной работы, которая описывала бы использование светотерапии точек акупунктуры при лечении от курения.

Светотерапия - это использование искусственного света для лечения различных расстройств. Издавна используется для лечения сезонных аффективных расстройств (SAD), расстройства сна, некоторых кожных заболеваний (целлюлиты, воспаления, угри и др.). Исследователи компании ZEPTER INTERNATIONAL в своих опытах с поляризованным светом применяют его при многих заболеваниях, травмах, различных воспалениях (например, глаз, ушей, синуса и др.), невралгических заболеваниях (люмбаго, эпилепсия и др.), травмах, сахарном диабете, бронхиальной астме, некоторых педи- 
атрических и гинекологических заболеваниях и т. д. Исследователи из Института физиологии им. А. А. Богомольца НАН Украины исследовали влияние поляризованного света на точки акупунктуры с целью достижения анальгезии. После подкожной инъекции 5-процентного формалина в ткани лапы животного, которая приводит к боли в этом участке, исследовались поведенческие реакции после воздействия поляризованного света на точку акупунктуры E-36 по отношению к контролю. Болевые циклы (наблюдалась местная воспалительная реакция на боль, лизание очага боли, двигательные расстройства) снизились по времени в сравнении с плацебо.

Особенности поляризованного света аппарата БИОПТРОН. Аппарат БИОПТРОН был создан в Венгрии в 1981 году группой физиков во главе с Мартой Феньо. Поляризованный свет создается в нем с помощью отражения на специальном многослойном зеркале. Световые волны осциллируют (колеблются) только в одной плоскости (линейная поляризация). Излучение имеет спектр длин волн от 480 до 3400 нм (т. е. видимую часть - 480-780 нм), а также инфракрасную (тепловую) часть, а именно от 780-1500 нм - IC-A до 15003400 HM - IC-B).

Его мощность составляет $40 \mathrm{MB} / \mathrm{cm}^{2}$, энергия является постоянной 2,4 Дж·см-2·мин-1, глубина проникновения в ткани - до 2,5 см. Ультрафиолетовое излучение из-за его неблагоприятного воздействия на кожу полностью устраняется с помощью специального фильтра.

При контакте с клеткой такой ПАЙЛЕР-свет усиливает электрический потенциал, который у больной клетки составляет 20 эВ, а после аппликации поляризованного света возрастает до уровня здоровой клетки, т. е. до 70 эВ. Он ускоряет образование АТФ в митохондриях клеток, что стимулирует процессы регенерации и благоприятно влияет на процесс заживления раны. Также усиливается локальный и общий иммунитет (увеличение содержания IgM до $84,83 \%$, IgA до 20,76\%, что зарегистрировано уже через 24 ч), улучшаются реологические характеристики крови (деформируемость эритроцитов и вязкость), что улучшает микроциркуляцию, индуцируется стимуляция активности регулятора роста в клеточной культуре с низкой пролиферацией и снижается регуляция при интенсивной пролиферации нормальных и злокачественных клеток.
ПАЙЛЕР-свет также положительно воздействует на центральную нервную систему: нейробиологические эффекты заключаются в возникновении новых нейротрансмиттеров NO (оксид азота) и СО (моноксид углерода), которые обладают антидепрессивным эффектом.

Воздействие на продуцирование серотина (ингибиторный ейротрансмиттер, который контролирует прием пищи, сон, страх, депрессивность) осуществляется таким образом, что поляризованный свет влияет на рост образования энзимов трансферазы, что является ключевым фактором в образовании серотина и мелатонина. Кроме того, снижается боль при непосредственном воздействии на нервные рецепторы, которые воспринимают и передают ощущение боли, а также опосредствовано через ANS и CNS (воздействие на нейромембрану путем восстановления нормального электропотенциала) активируются нейротрансмиттеры и рост эндорфинов (внутренних анальгетиков).

Фототерапия бессонницы. Впервые терапия поляризованным светом была опробована на больном 29 лет с ситуационным неврозом, который обратился за помощью по причине длительной бессонницы. Для лечения использовался аппарат БИОПТРОН-2. Передняя и задняя сторона шеи освещались в соответствии с инструкциями производителя в течение 6 мин. для каждой стороны. Всего было проведено 10 сеансов в вечерние часы (около 21:00). Во время терапии у больного наряду с основным расстройством - бессонницей - наблюдались и другие расстройства: беспокойство, страх, плохое настроение, депрессивные мысли, курение.

Ежедневную регистрацию указанных расстройств мы осуществляли по следующим критериям и на основании субъективных оценок больного (табл. 1): 0 - нет расстройств; 1 - слабо выраженные расстройства; 2 - более сильно выраженные расстройства; 3 - сильно выраженные расстройства; 4 - наиболее сильно выраженные расстройства.

Анализируя данные этой части работы, авторы пришли к выводу, что лечение бессонницы с помощью ПАЙЛЕР-света дало отличные результаты. Уже после первого сеанса лечения больной легче уснул и всю ночь спал. Утром чувствовал себя отдохнувшим, в хорошем настроении. Этот благоприятный эффект продолжался до конца лечения.

В скором времени воздействию поляризованного света подверглась больная 60 лет 
Таблица 1

Динамика расстройств сна у пациента во время светотерапии

\begin{tabular}{|c|c|c|c|c|c|c|c|c|c|c|}
\hline \multirow{2}{*}{ Расстройство } & \multicolumn{10}{|c|}{ Терапия, сутки } \\
\cline { 2 - 13 } & 1 & 2 & 3 & 4 & 5 & 6 & 7 & 8 & 9 & 10 \\
\hline Бессонница & 0 & 0 & 0 & 0 & 0 & 0 & 0 & 0 & 0 & 0 \\
\hline Беспокойство & 4 & 3 & 2 & 1 & 1 & 1 & 0 & 0 & 0 & 0 \\
\hline Страх & 3 & 2 & 2 & 0 & 0 & 0 & 0 & 0 & 0 & 0 \\
\hline $\begin{array}{c}\text { Плохое на- } \\
\text { строение }\end{array}$ & 4 & 3 & 3 & 2 & 1 & 1 & 0 & 0 & 0 & 0 \\
\hline $\begin{array}{c}\text { Депрессивные } \\
\text { мысли }\end{array}$ & 0 & 0 & 0 & 0 & 0 & 0 & 0 & 0 & 0 & 0 \\
\hline $\begin{array}{c}\text { Курение (в } \\
\text { среднем перед } \\
\text { терапией: 50 } \\
\text { штук/день)** }\end{array}$ & 27 & 23 & 22 & 20 & 19 & 15 & 17 & 16 & 9 & 10 \\
\hline
\end{tabular}

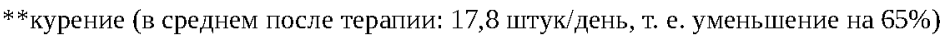

с многолетней бессонницей. Она не жаловалась на другие недомогания. Лечение аппаратом БИОПТРОН проводилось идентично. У этой больной восстановление функций засыпания и поддержания сна произошло после трех сеансов лечения и проявлялось в процессе терапии. У обоих больных с бессонницей мы наблюдали полученные результаты на протяжении 15 и 30 суток после прекращения светотерапии. У первого больного не было изменений достигнутого состояния, сон нормализовался. У второй больной «в двух рецидивах были проблемы с засыпанием, но сон в целом был хороший». Констатировано также и значительное уменьшение количества других расстройств у первого больного, особенно было отмечено заметное уменьшение потребности в курении (уменьшение количества выкуренных сигарет на 65\% по сравнению с состоянием перед светотерапией).

Фототерапия курения. Используя результаты предыдущих научных исследований влияния поляризованного света на организм (центральное воздействие, эффекты, которые при фотостимуляции кожи переносятся в кровь, стимуляция точек акупунктуры), мы решили испытать новый метод, т. е. светотерапию ушной раковины при лечении курения.

Протестировано 30 курильщиков-добровольцев. Лечение проводилось аппаратом БИОПТРОН-1, путем воздействия светом на одну ушную раковину (выбор был вариабельным, правая - у правшей), 10 ежедневных сеансов, время воздействия светом составляло 6 мин.
Первые четверо обследованных пациентов (табл. 2) были зарегистрированы как лица с психиатрическими расстройствами [1 Neurosis anxiosa (невроз страха), 2 - Neurosis situationis (ситуационный невроз), 3 - Psychosis paranoides, in remissionem (параноидный психоз, в стадии ремиссии), 4 - Psychosis depressiva chr., in remissionem (хронический депрессивный психоз в стадии ремиссии)].

Обобщая вышеприведенные результаты, пришли к следующим выводам:

1. Зарегистрировано уменьшение потребности в курении в диапазоне от 15 до 100\%, в среднем $-68,6 \%$.

2. У всех курильщиков под влиянием ПАЙЛЕРсвета возрастало желание совсем бросить курить, полный отказ от курения был зарегистрирован у четырех пациентов (№№ 25-30), которые еще в процессе терапии бросили курить и проявили интерес к психотерапевтическому лечению.

Таблица 2

Динамика количества выкуренных сигарет при лечении курения аппаратом БИОПТРОН

\begin{tabular}{|c|c|c|c|}
\hline $\begin{array}{c}\text { № п/П } \\
\text { куриль- } \\
\text { щиков }\end{array}$ & $\begin{array}{c}\text { До те- } \\
\text { рапиии, } \\
\text { штук/день }\end{array}$ & $\begin{array}{c}\text { После } \\
\text { терапии } \\
\text { штук/день }\end{array}$ & $\begin{array}{c}\text { Процент } \\
\text { уменьше- } \\
\text { ния }\end{array}$ \\
\hline 1 & 25 & 17,7 & 30 \\
\hline 2 & 50 & 17,8 & 65 \\
\hline 3 & 33 & 25,7 & 15 \\
\hline 4 & 30 & 23,4 & 20 \\
\hline
\end{tabular}


Продолжение табл. 2

\begin{tabular}{|c|c|c|c|}
\hline $\begin{array}{c}\text { № п/п } \\
\text { куриль- } \\
\text { щиков }\end{array}$ & $\begin{array}{c}\text { До те- } \\
\text { рапиии, } \\
\text { штук/день }\end{array}$ & $\begin{array}{c}\text { После } \\
\text { терапии } \\
\text { штук/день }\end{array}$ & $\begin{array}{c}\text { Процент } \\
\text { уменьше- } \\
\text { ния }\end{array}$ \\
\hline 5 & 15 & 6 & 60 \\
\hline 6 & 18 & 7,6 & 60 \\
\hline 7 & 15 & 5,1 & 60 \\
\hline 8 & 30 & 15 & 50 \\
\hline 9 & 36 & 14 & 60 \\
\hline 10 & 38 & 12 & 70 \\
\hline 11 & 30 & 5 & 80 \\
\hline 12 & 30 & 4 & 90 \\
\hline 13 & 40 & 20 & 50 \\
\hline 14 & 40 & 10 & 75 \\
\hline 15 & 30 & 2 & 95 \\
\hline 16 & 30 & 10 & 67 \\
\hline 17 & 30 & 15 & 50 \\
\hline 18 & 25 & 5 & 80 \\
\hline 19 & 24 & 6 & 75 \\
\hline 20 & 20 & 10 & 50 \\
\hline 21 & 20 & 4 & 80 \\
\hline 22 & 25 & 6 & 76 \\
\hline 23 & 30 & 8 & 73 \\
\hline 24 & 35 & 2 & 94 \\
\hline 25 & 20 & - & 100 \\
\hline 26 & 20 & - & 100 \\
\hline 27 & 25 & - & 100 \\
\hline 28 & 30 & - & 100 \\
\hline 29 & 15 & - & 100 \\
\hline 30 & 15 & - & 100 \\
\hline
\end{tabular}

\section{Литература}

1. Skrobic M. BIOPTRON fototerapija. - Beograd.- 1999. - $20 \mathrm{p}$.

2. Obolenskaya K., Samoilova K., Snopov 3., Shevchenko E. Modulation of functional state of circulating leucocytes after single exposure of skin to visible incoherent polarized light // Institute of Cytology, Russian Academy of Sciences. - St. Petersburg, 1998.

3. Vologdina A., Samoilova K., Obelenskaya K. Exsposure of skin to therapeutic doses of visible incoherent polarized light is followed by rapid changes in structural and functional parameters of red blood cells and plasma // Institute of Cytology, Russian Academy of Sciences. St. Petersburg, 1998.

4. Samoilova K., Snopov S. A. Key role of circulating blood modification in therapeutic effects of ultraviolet and visible light // Institute of Cytology, Russian Academy of Sciences.- St. Petersburg, 1998.

5. Limansky Y. P., Tamarova Z. A., Gulyar S. A. Suppression of pain by exposure of acupuncture points to polarized light // Pain Res Manag. - 2006; 11(1): 49-57.

6. Silangy C., Many D., Fowler G., Lancaster T. Nicotine replacement therapy for smoking cessation // The Cochrane Library, Issue 3, Oxford U.K., 1999. 